\title{
Morphological and molecular characterization of developing vertebral fusions using a teleost model
}

\author{
Elisabeth Ytteborg 1,2, Jacob Torgersen'1, Grete Baeverfjord'1 and Harald Takle*1,3
}

\begin{abstract}
Background: Spinal disorders are a major cause of disability for humans and an important health problem for intensively farmed animals. Experiments have shown that vertebral deformities present a complex but comparable etiology across species. However, the underlying molecular mechanisms involved in bone deformities are still far from understood. To further explicate the mechanisms involved, we have examined the fundamental aspects of bone metabolism and pathogenesis of vertebral fusions in Atlantic salmon (Salmo salar).

Results: Experimentally, juvenile salmon were subjected to hyperthermic conditions where more than 28\% developed fused vertebral bodies. To characterize the fusion process we analyzed an intermediate and a terminal stage of the pathology by using $x$-ray, histology, immunohistochemistry, real-time quantitative PCR and in situ hybridization. At early stage in the fusion process, disorganized and proliferating osteoblasts were prominent at the growth zones of the vertebral body endplates. PCNA positive cells further extended along the rims of fusing vertebral bodies. During the developing pathology, the marked border between the osteoblast growth zones and the chondrocytic areas connected to the arches became less distinct, as proliferating cells and chondrocytes blended through an intermediate zone. This cell proliferation appeared to be closely linked to fusion of opposing arch centra. During the fusion process a metaplastic shift appeared in the arch centra where cells in the intermediate zone between osteoblasts and chondrocytes co-expressed mixed signals of chondrogenic and osteogenic markers. A similar shift also occurred in the notochord where proliferating chordoblasts changed transcription profile from chondrogenic to also include osteogenic marker genes. In progressed fusions, arch centra and intervertebral space mineralized.

Conclusion: Loss of cell integrity through cell proliferation and metaplastic shifts seem to be key events in the fusion process. The fusion process involves molecular regulation and cellular changes similar to those found in mammalian deformities, indicating that salmon is suitable for studying general bone development and to be a comparative model for spinal deformities.
\end{abstract}

\section{Background}

The vertebral column is the defining character of vertebrates providing the organism with a unique ability of movement, form and function. Obviously, abnormalities to this organ can lead to severe and often painful pathological conditions. Spinal disorders are a major cause of disability for humans and an important health problem for intensively farmed animals. A number of animal models have been used to further explore the pathology and revealed that vertebral deformities present a complex but comparable cross species etiology [1,2]. Morphological changes like altered bone formation and cell density, thin-

\footnotetext{
* Correspondence: harald.takle@nofima.no

1 Nofima Marin AS, Norwegian University of Life Sciences, NO-1432 Ås, Norway Full list of author information is available at the end of the article
}

ning of osteoblasts along with increased cell proliferation and cell death are changes found in spinal deformities and intervertebral disc degeneration (IDD) in mammals $[3,4]$. Discs from patients with spinal deformities further have ectopic calcification of the vertebral endplates and sometimes in the disc itself [5]. Cells of the mammalian disc are derived directly from the phylogenetically conserved notochord [6]. Whereas only remnants of the notochord exists in the nucleus pulposus (NP) in humans by the age of 4 , the notochord persist throughout all life stages in teleosts. Spinal disorders in teleosts like sea bass, sea bream, rainbow trout, halibut and salmon [7-12] have mostly been descriptive and few molecular studies have been carried out. However, in Atlantic salmon (Salmo salar) compression (platyspondyly) and/or verte- 
bral fusion (ankylosis) accounts for 9 out of 20 recently described vertebral deformities [13]. Spinal fusions involves transformation of intervertebral notochord tissue into cartilage, shape alterations of vertebral body endplates, mineralization of the intervertebral cartilage and replacement of intervertebral cartilage by bone [14], pathological processes resembling those of IDD in mammals.

Skeletogenesis in salmon involves activity from the three main bone and cartilage cell types; chondrocytes, osteoblasts and osteoclasts. Bone formation further occurs via two basic mechanisms; compact bone of the amphicoel and trabeculae is formed directly through intramembranous ossification, whereas the cartilaginous template is replaced by bone in the arch centra through endochondral ossification. Bone formation is brought about by a complex set of highly regulated molecular pathways, involving extracellular matrix (ECM) constituents (e.g. collagens and osteocalcin), signaling molecules (e.g. hedgehogs and bmps) and transcription factors (reviewed [15-17]). Some of the key transcription factors in bone metabolism include runx2 and osterix [18], involved in the differentiation of mesenchymal stem cells (MSC) into osteoblasts that express bone matrix (colla) and matrix mineralizing (osteocalcin and osteonectin) genes. Early chondrocyte differentiation is controlled by sox9, which regulates transcription of col2a [19], the major ECM component of cartilage. Further, before endochondral ossification may occur, mef2c assures that chondrocytes mature into col10a producing hypertrophic cells [20]. Both mineralized bone and cartilage is remodeled through the activity of osteoclasts. These multinucleated cells provide and acidic environment, express cathepsins and matrix metalloproteinases (mmps) and are tartrate acid phosphatase resistant (TRAP). Hence mineralized matrix may be broken down $[21,22]$. The skeletal pathways described in mammals are currently being understood in teleosts. In a recent study, we investigated 20 genes for their role in salmon spinal column skeletogenesis [23]. However, the genetic interactions of bone and cartilage development are currently becoming more entangled, as chondrocytes and osteoblasts are shown to intersect through the formation of chondroid bone. This process has been described through normal maturation, differentiation plasticity and trans-chondroid ossification [24-26]. Though, the molecular pathways involved are still far from understood.

During the last decade problems with spinal disorders in salmon have been increasingly in focus due to the importance of this species in the aquaculture industry. To further elucidate the mechanisms involved in the development of vertebral deformities, we analyzed an intermediate and terminal stage of the fusion process at a morphological level by using radiography and histology and gene transcriptional changes using quantitative PCR (qPCR) and in situ hybridization (ISH). We found that loss of cell integrity and ectopic bone formation characterizes the development of spinal fusions. During the fusion process a metaplastic shift appeared in the arch centra where cells in the intermediate zone between osteoblasts and chondrocytes co-expressed mixed signals of chondrogenic and osteogenic markers. A similar shift also occurred in the notochord where proliferating chordoblasts changed transcription profile from chondrogenic to also include osteogenic marker genes. We suggest that hyperthermic induced development of spinal fusions involve a metaplastic shift in cells from the chondrocytic lineage. With this work, we bring forward salmon to be an interesting organism to study development of spinal fusions.

\section{Results}

The elevated temperature regime used in this study induced mainly vertebral deformities of the fusion type. The incidence of complete fusions was 10.0 (not significant $=$ n.s. $), 17.9(\mathrm{p} \leq 0.001)$ and $28.1 \%(\mathrm{p} \leq 0.0001)$ at 2 , 15 and $60 \mathrm{~g}$, respectively (Figure 1 ). The incidence in the two later samplings are underestimated, since these numbers do not take into consideration that fish sampled at 2 and $15 \mathrm{~g}$ could develop into fusions at the following samplings. Some fish displayed more than one type of pathology, but pathological changes other than fusions were low

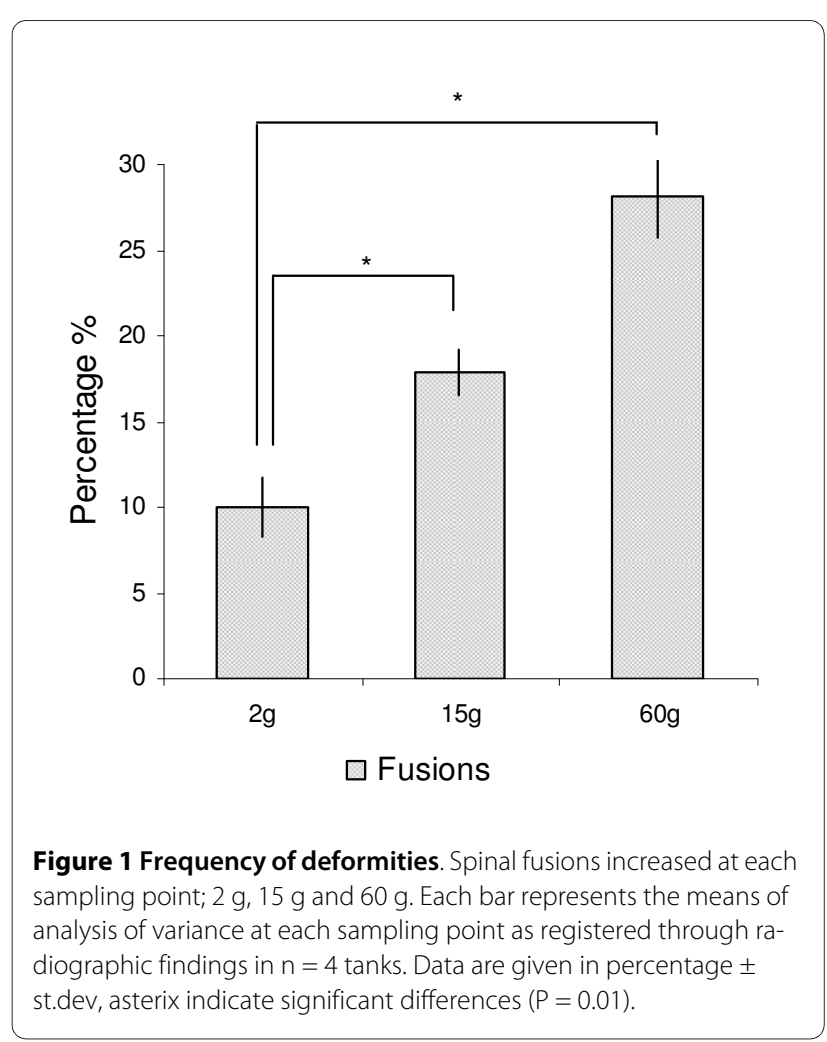


in numbers and were not investigated. The fusion process is a dynamic process as visualized by $\mathrm{x}$-ray in Figure 2 .

\section{Histology and immunohistochemistry}

Histological examination revealed more detailed morphological characteristics of intermediate and fused vertebral bodies (Figure 3A, B). The osteoblasts at the growth zones of the vertebral endplate appeared wellorganized in non-deformed vertebrae and little aberrancy was found when staining with toluidine blue (Figure 3C). The corresponding growth zones in intermediate verte-
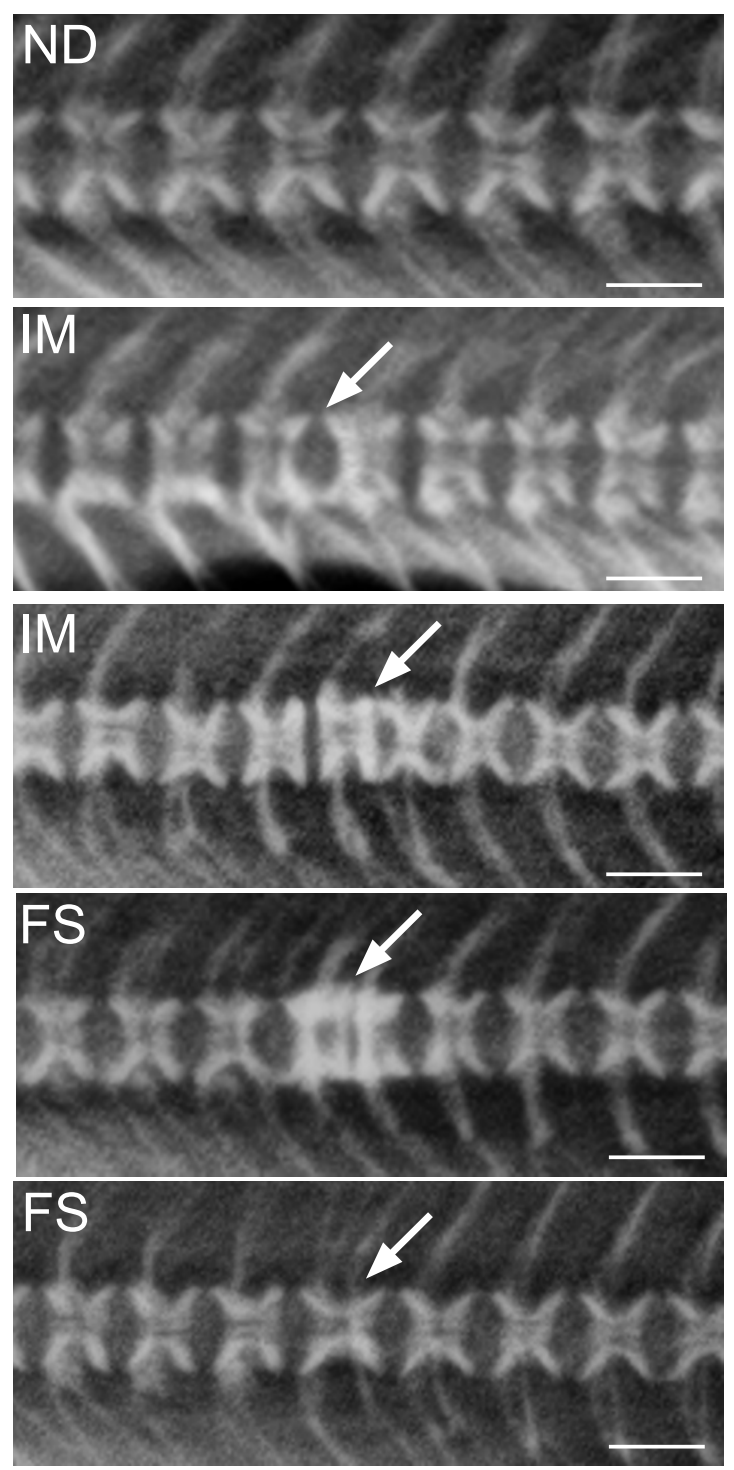

Figure 2 X-ray and diagnostics. The development of vertebral fusions is a dynamic process where the final result is a complete fusion of two or more vertebral bodies. Vertebrae were divided into non-deformed (ND), intermediate (IM) and fused (FS). White arrow points to malformed vertebral bodies. Scale bar $=0.1 \mathrm{~cm}$. brae displayed alterations in vertebral endplates and more disorganized osteoblasts (Figure 3D). These findings became more pronounced at fused stage. The osteogenic zone of the vertebral endplate extended abaxial inbetween two vertebral body endplates (Figure 3E). In addition, arch centra had decreased in fused vertebral bodies and chordocytes appeared denser compared to non-deformed (Figure 3B). Alizarin red S visualized more calcified tissue in areas with reduced arch centra in intermediate and fused vertebrae (Figure 3F-H). In fusions, normal vertebral hour-glass shape was replaced by a more compact and squared shape morphology, as the arch centra were more or less replaced by bone (Figure $3 \mathrm{H})$. Alizarin red S stained calcified tissue and showed calcification of the centra and around hypertrophic chondrocytes (Figure 3I). No calcification was detected in the intervertebral space of incomplete fusions (Figure 3I). In fusions, growth zones of opposing vertebral bodies had fused and intervertebral space mineralized (Figure 3K).

A balance between bone resorption and bone formation is required for maintaining bone integrity during remodeling. Thus, we examined osteoclast activity using TRAP staining. Weak positive TRAP staining was detected at the ossifying border of hypertrophic chondrocytes in the arch centra in one sample from the intermediate group (Figure 4A, B). No positive staining was found in samples from the fused group (Figure 4C).

To analyze if the morphological changes observed during development of fusions could be linked to an imbalanced cell cycling, we used immunohistochemistry with antibodies specific to PCNA for detection of proliferation and caspase 3 for detection of apoptosis. A few PCNA positive cells were apparent at the osteoblast growth zone at the endplates in non-deformed vertebral bodies (Figure 4D). PCNA positive cells were almost entirely restricted to these areas and were rarely found in chordoblasts or chordocytes (Figure 4E). However, we detected a markedly increase in PCNA positive cells at the growth zone of the endplates, and in cells extending axial at intermediate and fused stages (Figure 4F and 4G). Further, high abundance of proliferating chordoblasts were found in the notochord of vertebrae with reduced intervertebral space (Figure 4H and 4I). A few positive caspase 3 signals were detected at the rims of the osteoblast growth zone of the endplates in non-deformed vertebral bodies (Figure 4J). Increased caspase 3 signals were found in these areas of intermediate and fused vertebral bodies. Caspase 3 positive cells were also prominent at the transition between the intervertebral and vertebral regions (Figure $4 \mathrm{~K}$ and $4 \mathrm{~L}$ ). The positive signal was further spreading along the rims of the vertebral bodies in axial direction (Figure 4M) and in cells harboring the joints of the trabeculae (Figure $4 \mathrm{~N})$. Caspase 3 was not detected in the notochord in any of the groups. The cells that stained positive had charac- 


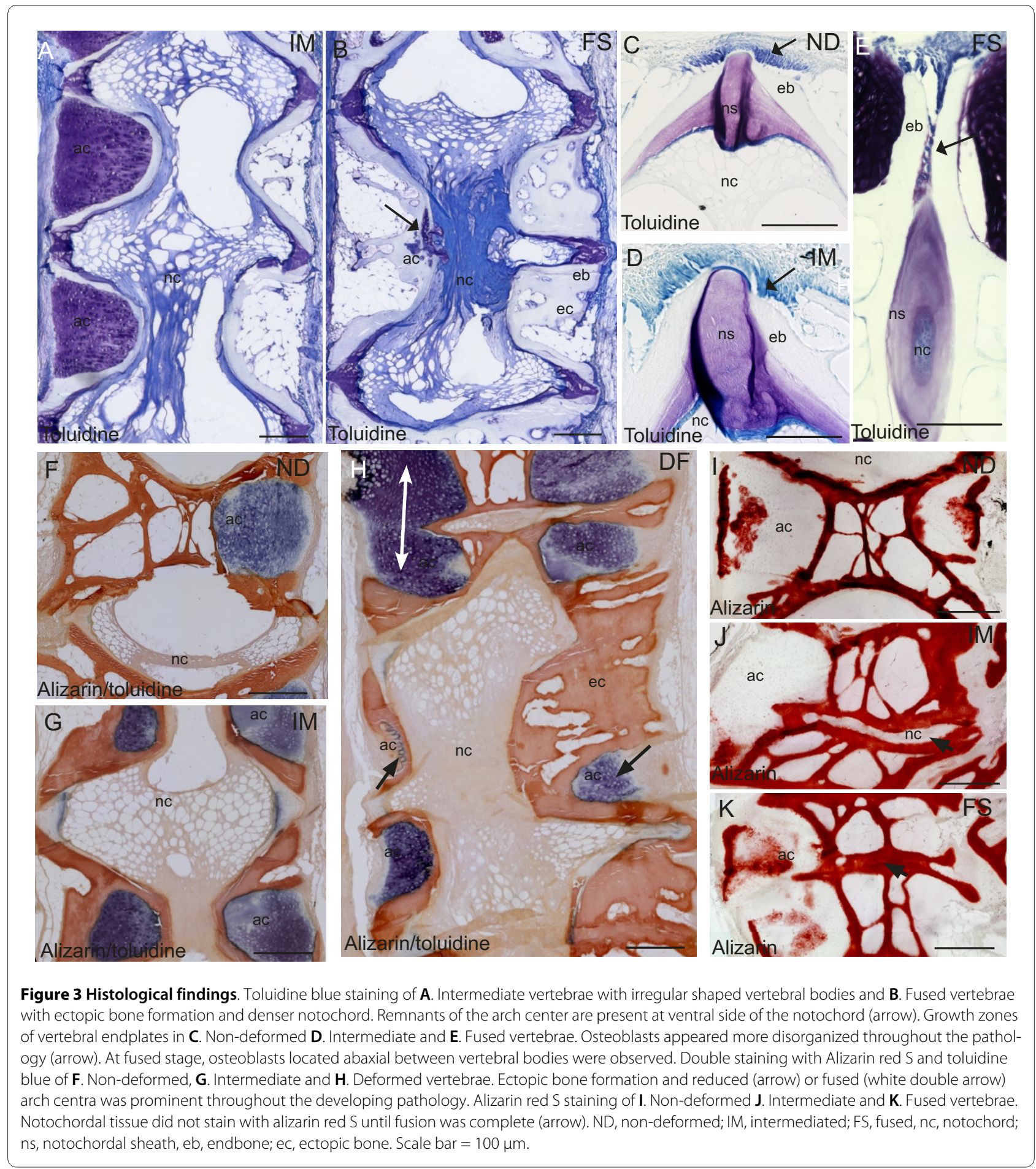

teristic apoptotic morphology with membrane blebbing (Figure 4O).

\section{Spatial and temporal gene transcription in developing fusions}

To examine transcriptional regulations involved in development of fusions, we analyzed non-deformed, intermediate and fused vertebrae with real-time qPCR, while the spatial gene transcription in intermediate and fused vertebrae were characterized by ISH. ISH of non-deformed vertebral bodies have previously been described in Ytteborg et al. [23]. No staining was detected for ISH with sense probes (additional file 1). Quantification of mRNA revealed that most genes were transcriptionally downregulated during the pathogenesis of vertebral fusions and that the suppression was more profound at the inter- 


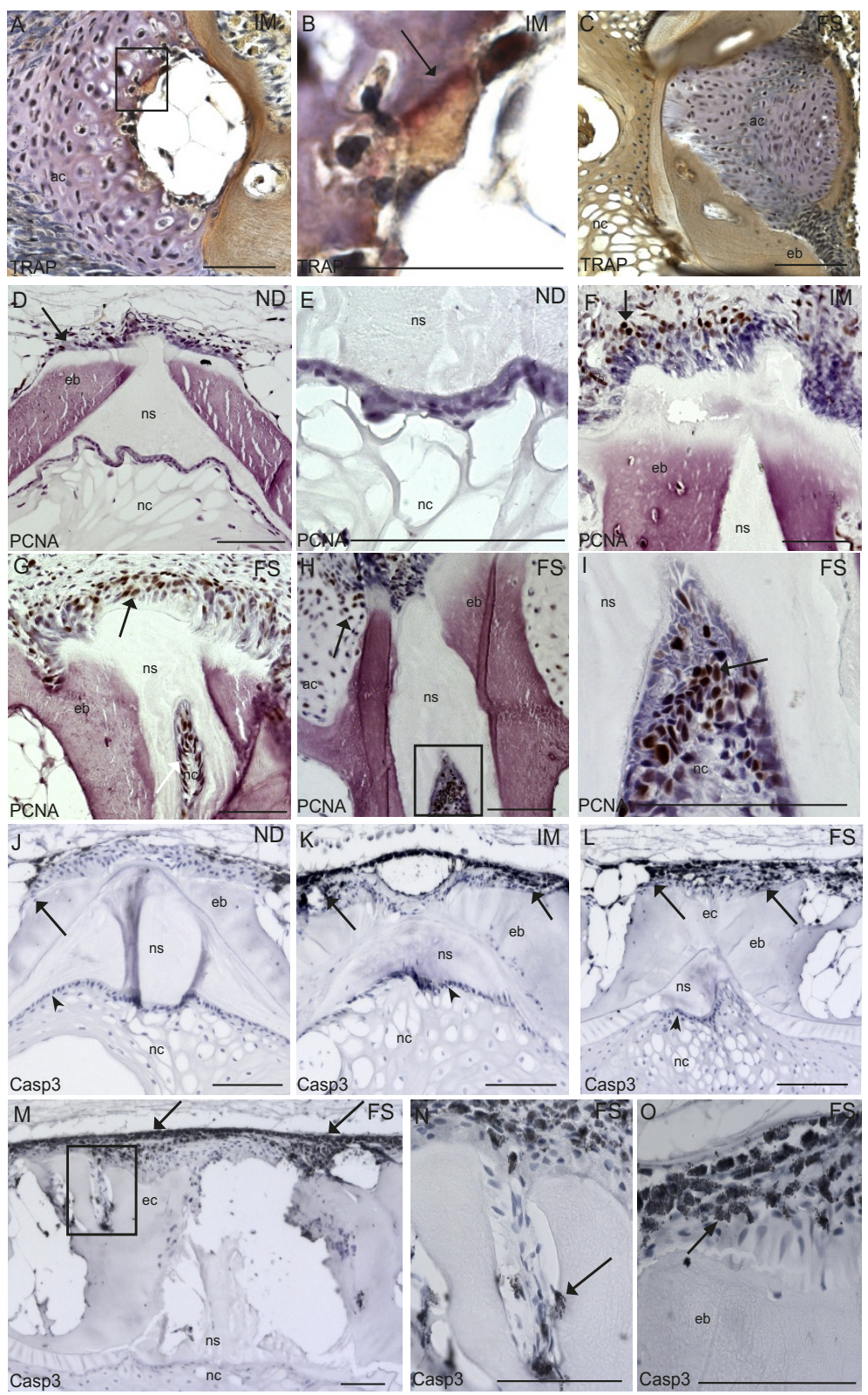

Figure 4 Immunohistochemistry with TRAP, PCNA and Caspase 3. A: One sample from intermediate group showed weak positive TRAP staining (arrow) at the ossifying border of the hypertrophic chondrocytes. B. Higher magnification of black box in A, positive TRAP staining (arrow). C. No TRAP activity was detected in any of the samples from the fused group. PCNA positive cells (brown) in $\mathbf{D}$. Non-deformed. Some proliferating cells can be seen at the growth zones of the vertebral body endplate (arrow). E. Higher magnification of chordoblasts in non-deformed. Positive cells were rarely found in chordoblasts. F. Intermediate vertebrae. PCNA was detected in higher amount at growth zones of the vertebral body end plate and extending abaxial and axial direction (arrow). G. Fused vertebrae. PCNA labeled cells were detected in the corresponding areas, but in higher abundance (arrow). H. PCNA positive cells were observed in the notochord and also in arch centra (arrow). I. Higher magnification of the black box in H, PCNA positive notochordal cells (arrow). Caspase 3 positive cells (black) in J. Non-deformed. Caspase 3 positive cells can be seen at the fringe of the growth zones of the vertebral body endplate (arrow). No positive cells could be detected in the chordoblasts (arrowhead) in any of the groups. K. Intermediate vertebrae; positive cells were detected in exceedingly higher amount at the corresponding areas (arrows). L. Fused vertebrae; positive cells were detected in the corresponding areas, but in higher amounts (arrow). M. Positive caspase 3 signal increased along the rims of the vertebral body and in trabeculae in fused vertebral bodies where we observed ectopic bone formation (arrow). N. Higher magnification of black box in E showing caspase 3 positive cells in the joints of ectopic bone (arrow). O. Higher magnification of caspase 3 labeled cells showing typical apoptotic phenotype with membrane blebbing (arrow). ND, non-deformed; IM, intermediated; FS, fused, nc, notochord; ns, notochordal sheath, eb, endbone; ec, ectopic bone. Scale bar $=100 \mu \mathrm{m}$. 
mediate stage than in fused specimens (Figure 5). We divided the 19 analyzed genes into two groups; structural genes and regulatory genes (transcription factors and signaling molecules).

\section{Structural genes}

Nine out of 11 structural genes had a down-regulated transcription in the intermediate group compared to only five in the fused group (Figure 5A). Four genes were down-regulated in both groups, including genes involved in bone (col1a1) and hypertrophic cartilage ECM production (col10a1) and mineralization (osteocalcin and alp). Col2a1 transcription was down-regulated in intermediate while up-regulated in the fused group (n.s.). Osteonectin was up-regulated in both groups. Of genes involved in osteoclast activity, $m m p 9$ showed opposite transcription, being down-regulated in intermediate while up-regulated in fused. Mmp13 and cathepsin $K$ showed similar transcription pattern in the two groups, $m m p 13$ up-regulated and cathepsin $K$ down-regulated (n.s. in fused).

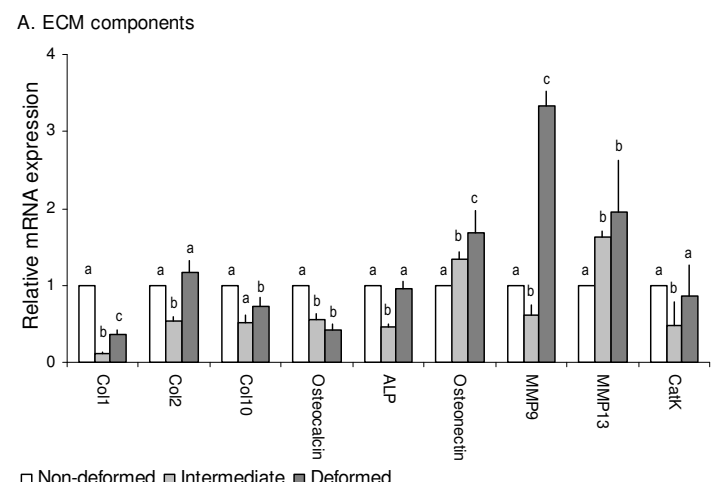

$\square$ Non-deformed $\square$ Intermediate $\square$ Deformed

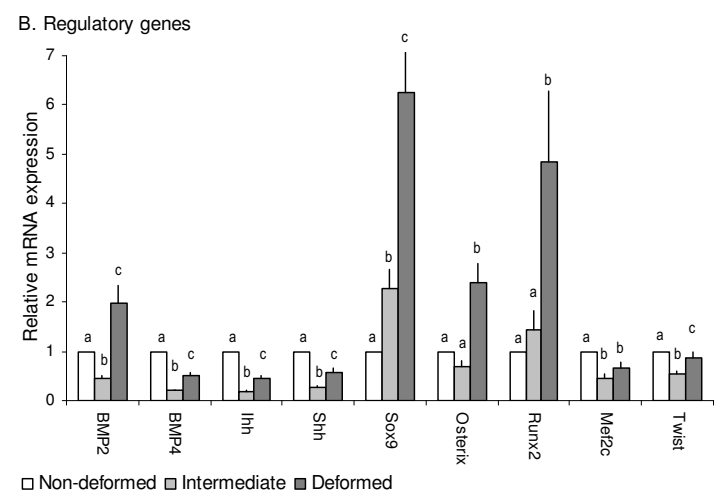

Figure 5 Quantitative gene transcription profiles in intermediate and fused vertebral bodies. Relative gene transcription of $\mathbf{A}$. Extracellular matrix constituents and $\mathbf{B}$. Regulatory genes in non-deformed (white bars) intermediate (light grey bars) and fused (dark grey bars) vertebrae, normalized with efla. Significant values $(P=0.05)$ indicated by $a-b-c, n=15$, means $\pm S E$. Transcription ratios are shown in relative mRNA expression along the $y$-axis, genes along the $x$-axis.
ISH analyzes of colla, col2a, col10a, osteonectin and osteocalcin revealed cells exhibiting characteristics of both osteoblasts and chondrocytes. These findings were more pronounced in fused than intermediate specimens. Colla was expressed in osteogenic cells along the rims of the vertebral body endplates and in osteoblasts at the lateral surfaces of trabeculae at the intermediate stage (Figure 6A). In incomplete fusions, we could locate osteogenic colla positive cells in the growth zone of the vertebral endplate extending abaxial in-between vertebral bodies (Figure 6B, C). In addition, col1 $a$ was expressed in high abundance in the intervertebral space of incomplete fusions (Figure 6D). The chondrocytic marker col2a was observed in chordoblasts in intermediate samples (Figure $6 \mathrm{E})$. Furthermore, col2 $a$ was expressed at the growth zone of the vertebral body endplates in both intermediate and fused samples (Figure 6F, G). Positive staining of col2a in the notochord became stronger as intervertebral space narrowed down (Figure 6F, G). Transcription of col10a was observed in hypertrophic chondrocytes and in osteogenic cells lining apical surfaces of trabeculae in intermediate and fused vertebrae (Figure 6H, I). Col10a seemed to be less expressed in both intermediate and fused vertebrae, as also observed from the down-regulated transcription of this gene from the qPCR results. Osteonectin showed a similar transcription pattern as col10, but transcription seemed increased in the trabeculae (Figure 6J). Transcription of osteonectin was also associated with chondrocytes in regions where arch centra fused (Figure $6 \mathrm{~K}, \mathrm{~L})$. Strong osteonectin transcription correlated with an up-regulated mRNA transcription observed from qPCR. Osteocalcin was transcribed in osteogenic cells lining surfaces of trabeculae of fused vertebrae (Figure $6 \mathrm{M}$ ) and in cells located abaxial in-between two opposing vertebral body endplates (Figure 6N). When the vertebral growth zones blended with the arch centra, chondrocytes expressing osteocalcin was observed (Figure 6O).

\section{Regulatory genes - transcription factors and signaling molecules}

All of the regulatory genes (Figure 5B) were less expressed in the intermediate compared to the fused group. Except of osterix, regulatory genes showed similar transcription patterns in the two groups. Twist involved in osteoblast inhibition and $m e f 2 c$ involved in chondrocyte hypertrophy were down-regulated in both groups. However, the chondrogenic marker sox 9 was up-regulated in both groups. The osteogenic markers runx2 and osterix had up-regulated transcription in the fused group, runx2 in intermediate group. Osterix was down-regulated in intermediate group, however n.s. Except of $b m p 2$ in fused vertebral bodies, signaling molecules $(s h h, i h h$, pdgfrb and bmp4) were down-regulated in both intermediate and fused group. 


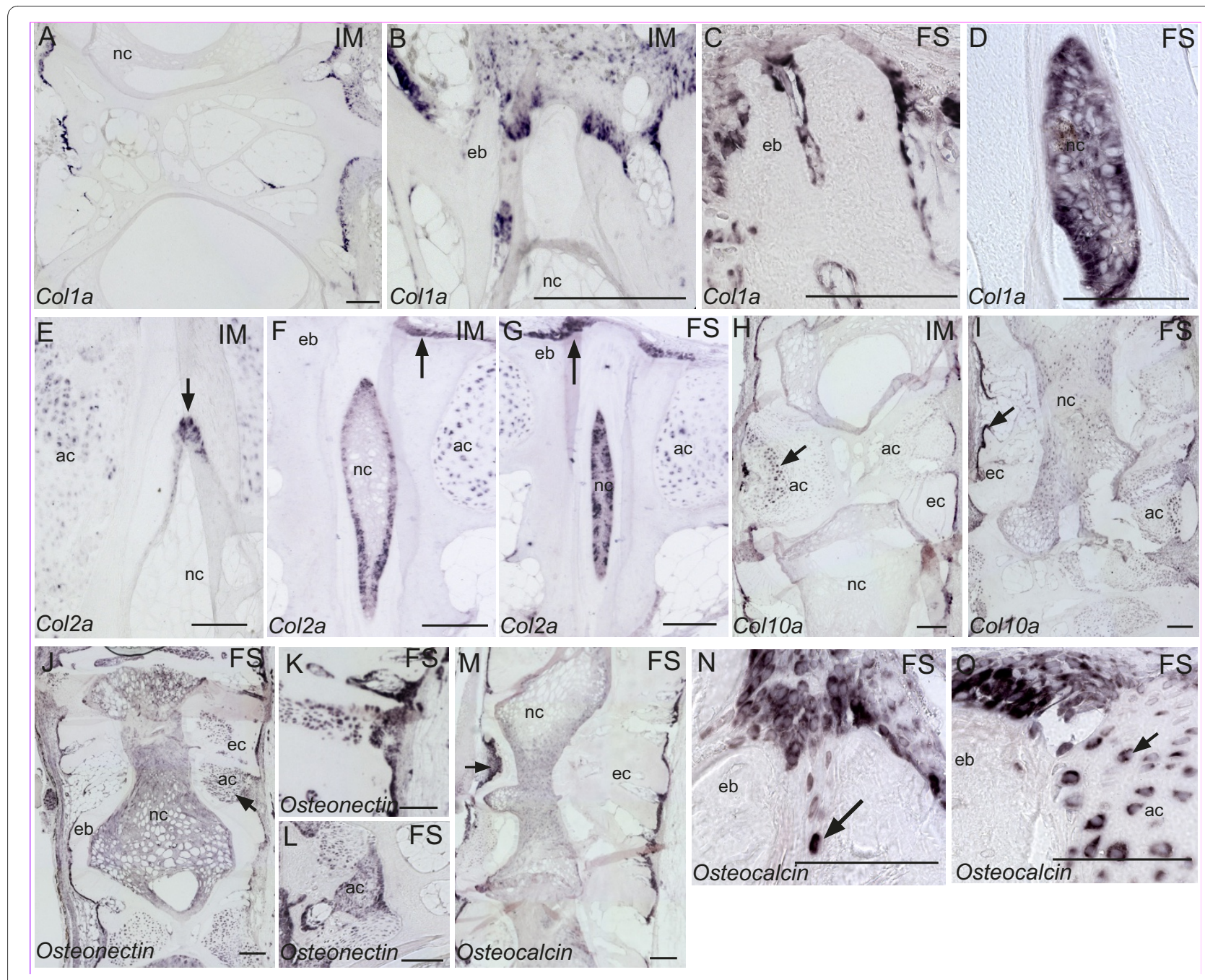

Figure $\mathbf{6}$ In situ hybridization of genes involved in the extracellular matrix. A. Colla transcription observed in trabeculae and at the growth zones of vertebral body endplates of intermediate vertebrae. B. Colla in osteoblasts extending from the growth zones of the vertebral body endplate in intermediate and C. fused vertebrae. D. Colla transcription in the notochord of a fusion. E. Col2a transcription in chordoblasts of intermediate vertebrae (arrow). F. Col2a transcription increased as intervertebral space narrowed down. In addition, col2a was observed at the osteoblast growth zone at the vertebral body endplates (arrow). G. In fused vertebrae, most cells in intervertebral space expressed col2a and expression in the osteoblasts increased (arrow). H. Col10a transcription along the rims of intermediate vertebrae and in hypertrophic chondrocytes (arrow). I. Col10a was more expressed in areas with ectopic bone formation (arrow). J. Osteonectin in fused vertebral bodies. Notice transcription along the rims of the vertebral bodies as well as in chondrocytes (arrow). Stronger staining was observed in areas with ectopic bone formation. K. Osteonectin transcription in areas with ectopic bone formation. L. Osteonectin transcribing chondrocytes. M. Osteocalcin was expressed in chondrocytes and along the rims of fused vertebrae. N. Osteocalcin transcription at the growth zone of two vertebral body endplates in a fusion. Notice cells expressing osteocalcin abaxial in-between the vertebral bodies (arrow). O. Osteocalcin expressing cells blending with chondrocytes. Both osteoblasts and chondrocytes expressed osteocalcin in these areas. ND, non-deformed; IM, intermediated; FS, fused, nc, notochord; ns, notochordal sheath, eb, endbone; ec, ectopic bone. Scale bar $=100 \mu \mathrm{m}$.

When analyzing selected genes by ISH, runx2 was never detected in chordocytes, chordoblasts or chondrocytes in non-deformed vertebral bodies. Positive runx2 staining was however detected at the osteoblast growth zone of the vertebral endplate (Figure 7A). In intermediate and fused samples we detected transcription at the corresponding growth zone and along the lateral surfaces of the trabeculae (Figure 7B). We observed an increased transcription of runx2 in the chordocytes of incomplete fusions (Figure 7C) and in the chordoblasts and chordocytes in more severe fusions (Figure 7D). These findings corresponded to the up-regulated transcription found by qPCR. Sox9 was expressed in chondrocytes in nondeformed vertebral bodies (Figure 7E) and in chordoblasts. In intermediate and fused samples, strong signals of sox9 were detected in intervertebral space (Figure 7F). Sox 9 was also transcribed at the vertebral growth zones of the endplates (Figure 7G) and the signal was extending 


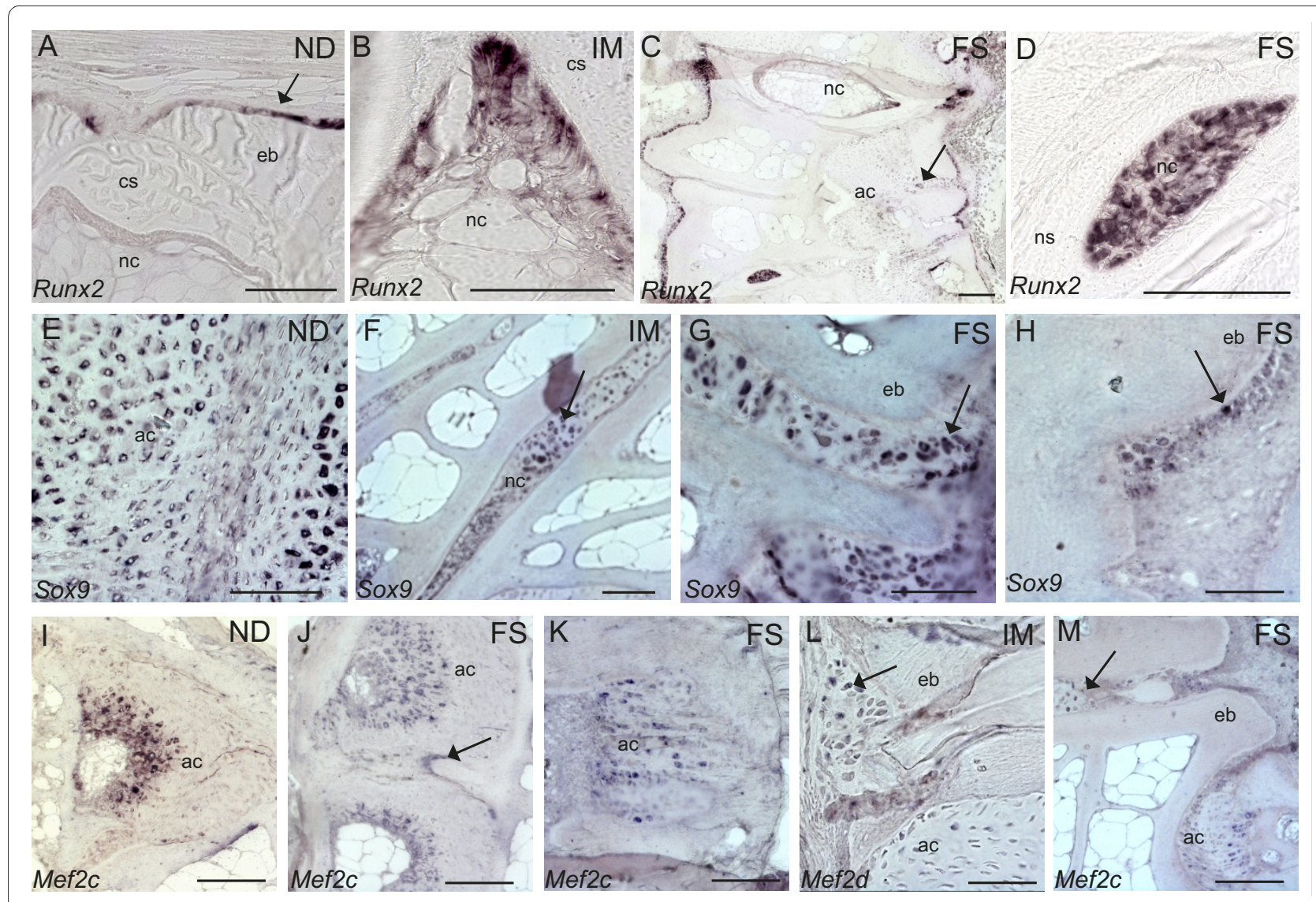

Figure 7 In situ hybridization of genes involved in regulatory processes. A. Runx 2 at the osteoblast growth zone of the vertebral body endplates in non-deformed vertebral bodies (arrow). Notice no transcription in chordocytes. B. Runx2 transcription in intermediate vertebrae showed transcription in chordoblasts. C. Runx2 transcription in fused vertebrae, notice positive staining in the chordocytes and in areas with ectopic bone formation (arrow). D. Strong staining of runx2 in cells in the notochord of a fusion. E. Sox9 transcription chondrocytes of non-deformed vertebrae. F. Fused vertebrae had high sox9 transcription in intervertebral space. G. Higher magnification of cells expressing sox9 at the vertebral growth zone of a fusion. $\mathbf{H}$. Sox9 was also expressed along the rims of ectopic bone formation. I. Mef2c transcription in hypertrophic zone in non-deformed vertebral bodies. J. Mef2c in fusing arch centra. Notice positive cells outside the hypertrophic zone (arrow). K. Mef2c in arch center narrowing down. L. Mef2c transcription at the growth zones blending with the arch centra. M. Mef2c positive cells in intervertebral space of an incomplete fusion (arrow). ND, non-deformed; IM, intermediated; FS, fused, nc, notochord; ns, notochordal sheath, eb, endbone; ec, ectopic bone. Scale bar $=100 \mu \mathrm{m}$.

axial in severe fusions (Figure $7 \mathrm{H})$. Mef2c was expressed in a wide zone of hypertrophic chondrocytes in nondeformed vertebral bodies (Figure 7I). Hypertrophic chondrocytes also transcribed $m e f 2 c$ in intermediate and fused vertebral bodies (Figure 7J). Further, mef2c was observed at the boundaries between two fused arch centra (Figure 7J). In fusions were arch centra narrowed down, mef2c transcription did not seem restricted to hypertrophic zones (Figure 7K). Some mef2c expressing cells was also detected at the vertebral endplates (Figure $7 \mathrm{~L}$ ) and abaxial between vertebral growth zones of opposing vertebral bodies in incomplete fusions (Figure $7 \mathrm{M})$.

\section{Discussion}

In this study we present a molecular characterization of mechanisms involved in development of vertebral fusions in salmon. We have previously shown that the nondeformed fish used in this study had indications of soft bone phenotype [23]. They were further characterized by disrupted chondrocytic maturation, increased zones of hypertrophic chondrocytes and delayed endochondral ossification in the arch centra [23]. The number of deformities increased throughout the experiment and an imbalanced bone and cartilage production characterized susceptible fish, predisposed for developing deformities [23]. In this study we wanted to analyze an intermediate and a terminal stage of the fusion process to further characterize developing deformities. Through this experiment, we found that vertebral deformities were developing through a series of events, of which five hallmarks were identified as particularly interesting. First, disorganized and proliferating osteoblasts were prominent in the growth zones of the vertebral body endplates. 
Second, a metaplastic shift made the borders less distinct between the osteoblastic growth zone and the chondrocytic areas in the arch centra. Third, the arch centra ossified and the endplates became straight, hence giving the vertebral bodies a squared shaped morphology. Fourth, the intervertebral space narrowed down and the notochord was replaced by bone forming cells. Fifth, in a complete fusion all intervertebral tissue was remodeled into bone.

One of the major morphological changes during the fusion process was ossification of the arch centra. Our findings suggest that this ectopic bone formation is a key event in development of vertebral fusions, which involve lack of normal cell differentiation and growth. Immunohistochemistry with PCNA showed that osteoblasts at the growth zone of the vertebral body endplates had a markedly increased cell proliferation during the fusion process. The increased proliferation of osteoblasts was apparently partly counteracted by increased cell death as shown by stronger caspase 3 signaling. Nevertheless, the osteoblasts at the vertebral endplates appeared less organized in intermediate and fused vertebral bodies by toluidine blue staining. In addition, in fused vertebral bodies we observed moderate changes of abaxial translocation of cells from the osteoblast growth zone. Abaxial direction of growth from the borders of vertebral body end-plates and formation of chondroid bone in these areas are also described in previous experiments [14,27]. The findings of increased proliferation and disorganized osteoblast growth were evident in vertebrae with modest alterations, which may suggest that this is an early event in the fusion process.

During the developing pathology, the marked border between the osteoblast growth zones and the chondrocytic areas connected to the arches became less distinct, as proliferating cells and chondrocytes blended through an intermediate zone. PCNA positive cells further extended along the rims of fusing vertebral bodies. This cell proliferation appeared to be closely linked to fusion of opposing arch centra. During the fusion process a metaplastic shift appeared in the arch centra where cells in the intermediate zone between osteoblasts and chondrocytes co-transcribed colla, col2a, runx2, osteocalcin and osteonectin, as visualized by ISH. Based on histology, Witten et al. [25] have previously suggested the involvement of a metaplastic shift in developing fusions. In more progressed fusions, most cells in the arch centra seemed to co-transcribe osteogenic and chondrogenic markers. Our suggestion is therefore that trans-differentiated cells produce the ectopic bone.

Several in vitro studies have demonstrated that chondrocytes associated with calcifying cartilage can acquire properties of osteoblasts [28] and are able to change their phenotype from a primarily cartilage synthesizing cell type to a bone synthesizing cell type [29]. However, hypertrophic chondrocytes able to trans-differentiate into osteoblasts through a process called trans-chondroid ossification has also been described [24]. Interestingly, this type of growth has been identified during distraction osteogenesis in rats $[24,30]$, a process where bone is formed rapidly upon stretching. During trans-chondroid ossification, chondrocytes are found to express both coll and col2 [24]. In a review by Amir et al. [31] it was speculated if tension stress during distraction inhibited final differentiation of chondrocytes and rather trans-differentiated these cells into osteoblastic cells. At fused stage, early markers for osteoblasts and chondrocytes (runx2, osterix, sox 9 and $b m p 2$ ) were upregulated whereas the osteoblast inhibitor (twist) and genes involved in chondrocyte hypertrophy (bmp4, mef2c, col10a, shh and ihh) were downregulated, results also supported by ISH. Deletion of $I h h$ has been shown to disrupt the normal pattern of various zones of chondrocyte differentiation in the growth plate [32], whereas Sox9 accelerate chondrocyte differentiation in proliferating chondrocytes but inhibit hypertrophy [33]. Sustained runx2 expression, as found in our studies, is further associated with trans-differentiation of chondrocytes into bone cells [34]. On the contrary, analyzing the ECM components of both osteoblasts and chondrocytes (col1a, col2a, col10a, osteocalcin and $a l p$ ) revealed that these transcripts had reduced activity in both intermediate and fused vertebrae. These findings might reflect the reduced radiodensity described in fish reared at elevated temperatures [23].

To further characterize the pathological bone formation in the chondrocytic areas in the arch centra, we analyzed osteoclast activity. Absence of osteoclasts visualized through TRAP staining was characteristic during the development of vertebral fusions, indicating that normal endochondral ossification was restrained. In addition, cathepsin $k$ had a down-regulated transcription level. In normal developing salmon vertebrae, these areas are modeled through endochondral bone formation, a process requiring invasion of osteoclasts and activity of TRAP, Mmps and Cathepsin K [21,35]. Transcription of mmps are up-regulated during IDD [36] and compression-induced IVD [37,38] in mammals. Intriguingly, $m m p 9$ and $m m p 13$ were also up-regulated during fusion of vertebral bodies in salmon. Excessive co-activity of $m m p 9$ and $m m p 13$ is linked to development and healing of chronic wounds in rainbow trout [39] and salmon [40]. Lack of osteoclast activity and reduced activity of genes involved in chondrocyte hypertrophy during development of vertebral fusions may therefore suggest that $m m p$ 's were up-regulated in fused vertebral bodies as a response to chronic injury rather than bone resorption.

Our results suggest that the ossification type during development of spinal fusions and fast growth could be 
trans-chondroid ossification. A mixed type of intramembraneous and endochondral ossification, as suggested by Yasui et al. [24] and demonstrated by Okafuji et al. [30] may also occur, however the lack of osteoclast activity makes this less likely. Our findings indicate that chondrocytes had not only differentiated towards osteoblast-like cells, but also completed the differentiation to cells that were capable of producing mineralized bone matrix. Whether the suggested trans-chondroid ossification is trans-differentiation as a sudden switch from the chondrogenic to the osteogenic phenotype or a continuous differentiation was not assessed in this experiment. However, based on our results, a pathway to bone formation through chondrocytes might be possible during development of vertebral fusions.

The completing step in the fusion process is transformation of notochordal tissue into bone [14]. As intervertebral space narrowed down, proliferating chordoblasts and denser packet chordocytes were revealed through toluidine blue staining and PCNA antibody binding, respectively. The structured chordoblast layer increased and more of these cells stained for col2a. As the pathology progressed, proliferating chordoblasts seemed to occupy most of the intervertebral space and vacuolated chordocytes disappeared. Moreover, cells in the notochord had a transcription profile resembling the transdifferentiating cell at the borders between the osteoblast growth zones and the chondrocytic areas connected to the arches. Transcription of marker genes changed from chondrogenic to also include osteogenic, as mRNA of osteocalcin, runx2, osteonectin and colla were detected. QPCR further showed up-regulated transcription of both runx2 and sox9 throughout the developing deformity. Comparative to our findings, disc cell proliferation and a switch in the synthesis of ECM components are associated with disc degeneration [41,42]. However, ISH revealed that whereas sox9 and col2a was present in chordoblasts from the non-deformed stage, runx2 and colla was only detected in fused samples, when intervertebral space was severely narrowed. This co-transcription of chondrocytic and osteogenic markers in the notochord supports the hypothesis of a metaplastic shift during vertebral fusions in salmon [25].

The metaplastic shift in the notochord and arch centra may be induced to produce more robust cells, able to withstand increased mechanical load. However, as bone replaced chondrocytic areas throughout the pathology, notochordal tissue did not calcify until the deformity developed into severe fusion. We therefore suggest that metaplasia leads to cell types more suited to the new environment but that changes are related to a threshold of the stimuli, in this case, grade of fusion. A shift in NP cell population coincides with spinal disorders like IDD and changes in the synthesis of matrix molecules differ with the degree of degeneration [43]. A comparative pathological process to our findings is mammalian "Bamboo spine", describing a condition where vertebral bodies have fused and reshaped through ectopic bone formation $[44,45]$. Similar rescue processes have also been found in the mammalian AF, where it is strengthened through cartilage formation upon elevated mechanical load [46,47]. Overall, the vertebral fusion process seen in salmon might reflect an effort to restore and strengthen a vertebral area of a weakened vertebral column.

\section{Conclusion}

Vertebral fusions develop through a series of events. Disorganized and proliferating osteoblasts at the growth zones and along the rims of affected vertebral bodies characterized the fusion process. Moreover, loss of cell integrity through cell proliferation was prominent at the border between the osteoblastic growth zone and the chondrocytic areas in the arch centra and in intervertebral space. During the fusion process a metaplastic shift appeared in the arch centra where cells in the intermediate zone between osteoblasts and chondrocytes coexpressed mixed signals of chondrogenic and osteogenic markers. A similar shift also occurred in the notochord where proliferating chordoblasts changed transcription profile from chondrogenic to also include osteogenic marker genes. As the pathology progressed, ectopic bone formation was detected in these areas. Since transcription turned from chondrogenic to osteogenic, our suggestion is that trans-differentiated cells produce the ectopic bone. In complete fusions, all intervertebral tissue was remodeled into bone. The molecular regulation and cellular changes found in salmon vertebral fusions are similar to those found in mammalian deformities, showing that salmon is suitable for studying general bone development and to be a comparative model for spinal deformities. With this work, we bring forward salmon to be an interesting organism to study general pathology of spinal deformities.

\section{Methods}

\section{Rearing conditions}

This trial was performed under the supervision and approval of the veterinarian that has appointed responsibility to approve all fish experiments at the research station in accordance to regulations from the Norwegian authorities regarding the use of animals for research purposes. The experiment was carried out at Nofima Marins research station at Sunndalsøra, Norway, in 2007, as described in Ytteborg et al. [23]. During egg rearing, water supply was continuous from temperature controlled tanks stabilized at $10 \pm 0.3^{\circ} \mathrm{C}$. The temperature was gradually increased at first feeding to $16 \pm 0.3^{\circ} \mathrm{C}\left(1^{\circ} \mathrm{C}\right.$ per day). Temperatures exceeding $8^{\circ} \mathrm{C}$ during egg rearing 
and $12^{\circ} \mathrm{C}$ after start feeding elevate the risk of developing spinal fusions.

\section{Radiography and classification}

Sampling was directed from radiographs so that the sampled area corresponded to the deformed or normal area. Fish were sedated (Tricaine methane sulfonate, Pharmaq, Norway) and radiographed during the experiment at $2 \mathrm{~g}$, $15 \mathrm{~g}$ and $60 \mathrm{~g}$. Fish that were not sampled were put back into oxygenated water to ensure rapid wakening. The $x$ ray system used was an IMS Giotto mammography system (model number 6020/3, IMS Giotto, Bologna, Italy) equipped with a FCR Profect image plate reader and FCR Console (Fuji Medical Inc., Japan). At 15 g size, fish were sampled for histological and gene transcriptional analysis. Samples for $I S H$ and histology were fixed in $4 \%$ PFA $(\mathrm{n}=24)$ and samples for RNA isolation were snap frozen in liquid nitrogen and stored at $-80^{\circ} \mathrm{C}(\mathrm{n}=45)$.

All fish were divided into three categories where the first group was non-deformed. These spinal columns had no observable morphological changes in the vertebral bodies or in intervertebral space. We further sampled vertebral areas at two different stages in the pathological development of fusions, termed intermediate and fused. Vertebrae diagnosed as intermediate included various degrees of reduced intervertebral space and compressions. Samples characterized as fused ranged from incomplete fusions to complete fusions.

\section{Statistical analyses}

Incidence of fusions were observed through radiography and calculated using a one-way analysis of variance model (GLM procedure, SAS 9.1 software, SAS Institute Inc., USA). Results are represented as means \pm standard deviation (st.dev).Statistics for mRNA transcription analysis are described in the real-time PCR chapter.

\section{Sample preparation}

Histological staining and $I S H$ was carried out on five $\mu \mathrm{m}$ Technovit 9100 New sections according to the protocol [48]. Serial sections were prepared in the parasagittal orientation from vertebral columns, starting at the periphery and ending in the middle plane of the vertebrae using a Microm HM 355S (Thermo Fisher Scientific Inc., MA, USA). For immunohistochemistry, tissue was decalcified for seven days in 10\% EDTA, dehydrated in ethanol, cleared and embedded in paraffin. Five $\mu \mathrm{m}$ serial sections were prepared as described above, de-waxed with Clear Rite (Richard-Allan, MI, USA), followed by two times washing in xylene (Merck Chemicals Ltd.) for five min each. Sections were then rehydrated before rinsed in $\mathrm{dH}_{2} \mathrm{O}$.

\section{Histology and immunohistochemistry}

Bone and cartilage formation in the spinal columns were assayed by Alizarin Red S/Toluidine Blue (Sigma-Aldrich,
MO, USA) staining. Sections were stained for $5 \mathrm{~min}$ in Alizarin red ( $\mathrm{pH} 4.2$ ) and for $2 \mathrm{~min}$ in $0.1 \%$ Toluidine blue (pH 2.3), with a brief rinse in $\mathrm{dH}_{2} \mathrm{O}$ in between. Single staining with the two dyes was also performed. All sections were dehydrated in ethanol and mounted with Cytoseal 60 (Electron Microscopy Science, PA, U.S.A) prior to microscopy. To demonstrate osteoclast activity, TRAP was visualized with the Acid phosphatase leukocyte kit No. 387 (Sigma-Aldrich) was applied according to the manufacturer's protocol, with the exception of a 2 $\mathrm{h}$ incubation at $37^{\circ} \mathrm{C}$. Subsequently, slides were rinsed in $\mathrm{dH}_{2} \mathrm{O}$ and counterstained with Mayers hematoxylin (Sigma-Aldrich) for $30 \mathrm{~s}$. Cell proliferation and apoptosis were assessed by immunohistochemical detection of proliferating cell nuclear antigen (PCNA) and cleaved Caspase 3, respectively [49-51]. Slides were placed in $0.1 \mathrm{M}$ citric acid, $0.05 \%$ Tween $20(\mathrm{pH} 6)$ and heated in microwave, $5 \mathrm{~min}$ at $900 \mathrm{~W}$ and $4 \mathrm{~min}$ at $650 \mathrm{~W}$. Endogenous peroxidase activity was blocked 10 min in $3 \% \mathrm{H}_{2} \mathrm{O}_{2}$ in methanol. The sections were washed $3 \times$ in PBS and incubated with a mouse anti PCNA monoclonal antibody (clone PC10, Zymed Laboratories Inc., CA, USA) or Cleaved Caspase 3 (Asp175 5A1, Cell Signaling Inc. Boston, MA, USA), following the manufacturer's instructions. Slides were washed $3 \times 5 \mathrm{~min}$ in PBS-Tween 20 before counterstained with Mayer's hematoxylin for 2 min, washed in water, dehydrated in a graded series of ethanol solutions, cleared with xylene, and mounted with Cytoseal60 (Electron Microscopy Science). Controls were incubated without substrate. Microscopic analyses were performed by the stereomicroscope Zeiss Axio Observer Z1 using brightfield illumination and digitized images obtained with an AxioCam MRc5 camera using AxioVision software (Carl Zeiss Microimaging GmbH, Göttingen, Germany).

\section{Primer design}

Primers (Table 1) for transcription analysis were based on known salmon sequences or on conserved regions of known teleost sequences paralogues. Primers were designed using the Vector NTI Advance 10 (Invitrogen, CA, USA) and NetPrimer (PREMIER Biosoft, CA, USA) software. All PCR products were cloned using pGEM Teasy (Promega, WI, USA) and sequenced with Big Dye Terminator chemistry and the ABI 3730 automated sequencer, both delivered by (Applied Biosystems, CA, USA). The obtained salmon clones were analyzed by BLAST and deposited in the Genbank database.

\section{RNA isolation and CDNA synthesis}

Tissue homogenization from 15 replicates from each group was achieved in a mortar with liquid nitrogen. RNA was extracted using Trizol reagent and Micro to Midi Kit' (Invitrogen). Brief, tissue was homogenized in a mortar with liquid nitrogen and total RNA was extracted 
Table 1: Primers used for cloning, sequencing, transcriptional analysis and probe synthesis

\begin{tabular}{|c|c|c|c|c|}
\hline Gene & Orientation & Genbank & Use & Sequence (5'-3') \\
\hline \multicolumn{5}{|c|}{ Extracellular Matrix constituents } \\
\hline \multirow[t]{4}{*}{ Col1a1 } & Forward & FJ195608 & RT & AGAGAGGAGTCATGGGACCCGT \\
\hline & Reverse & & RT & GGGTCCTGGAAGTCCCTGGAAT \\
\hline & Forward & & ISH & TAGCCGTGGTTTCCCTGGTT \\
\hline & Reverse & & ISH & CCGGGAGGTCCAAATCTACC \\
\hline \multirow[t]{4}{*}{ Col2a1 } & Forward & $\underline{\text { FJ195613 }}$ & RT & TGGTCGTTCTGGAGAGACT \\
\hline & Reverse & & RT & CCTCATGTACCTCAAGGGAT \\
\hline & Forward & & ISH & GCTGGCGAGACAGGAGAGA \\
\hline & Reverse & & ISH & GCCTCATCAGCCCTCATGTA \\
\hline \multirow[t]{4}{*}{ Col10a1 } & Forward & $\underline{E G 837148}$ & RT & TGGTGCTCTTTGACTGCCTGTAA \\
\hline & Reverse & & RT & САTCCTGTGTGTTGCAATATCACA \\
\hline & Forward & & ISH & AACAAGGGCTTCTTGGATCA \\
\hline & Reverse & & ISH & CATAATGCATCCTCAGGCAT \\
\hline \multirow[t]{2}{*}{ Alp } & Forward & FJ195609 & RT & CTAGTTTGGGTCGTGGTATGT \\
\hline & Reverse & & RT & TGAGGGCATTCTTCAAAGTA \\
\hline \multirow[t]{4}{*}{ Osteocalcin } & Forward & FJ195616 & RT & GTGAACCAACAGCAAAGAGA \\
\hline & Reverse & & RT & CCAGGTCCTTCTTAACAAACA \\
\hline & Forward & & ISH & CTCATACTTGTTGATCGTCCAG \\
\hline & Reverse & & ISH & TCTाTCTCTCTCGCTCTCCC \\
\hline \multirow[t]{4}{*}{ Osteonectin } & Forward & FJ195614 & RT & ATTACTGAGGAGGAGCCCATCATT \\
\hline & Reverse & & RT & ССТСАТССАССТСАСАСАCСТT \\
\hline & Forward & & ISH & CTGAACGATGAGGGTGTGGA \\
\hline & Reverse & & ISH & CGAGTGGTGCAGTGCTCCAT \\
\hline \multirow[t]{2}{*}{ Mmp9 } & Forward & $\underline{\mathrm{CA} 342769}$ & RT & AGTCTACGGTAGCAGCAATGAAGGC \\
\hline & Reverse & & RT & CGTCAAAGGTCTGGTAGGAGCGTAT \\
\hline \multirow[t]{2}{*}{ Mmp13 } & Forward & DW539943 & RT & TGATGTCCAAGTCAGCCGCTTC \\
\hline & Reverse & & RT & TGGTCTGCCACTTGCGATTGTC \\
\hline \multirow[t]{2}{*}{ Cathepsin K } & Forward & NM 001140399 & RT & ATGACCAACGCCTTCGAGTAC \\
\hline & Reverse & & RT & AAGGTGGAGAGGGTGGCATC \\
\hline \multicolumn{5}{|c|}{ Transcription factors } \\
\hline \multirow[t]{4}{*}{ Sox9 } & Forward & EU344852 & RT & CCTGCAAACAAGACAAGGT \\
\hline & Reverse & & RT & GGGTCGAGTAGATTCATACGA \\
\hline & Forward & & ISH & GGGGATACTATTTGACTGGATC \\
\hline & Reverse & & ISH & TCTGTCTTGATGTGTGTGGG \\
\hline \multirow[t]{2}{*}{ Runx2 } & Forward & FJ195615 & $\mathrm{RT} / \mathrm{ISH}$ & CCACCAGGGACAGACACAGAT \\
\hline & Reverse & & $\mathrm{RT} / \mathrm{ISH}$ & GAACGGACTGAGATCTGACGAA \\
\hline \multirow[t]{2}{*}{ Osterix } & Forward & FJ195612 & RT & TCCCATAGACTTTCCCACA \\
\hline & Reverse & & RT & TGCCTCAGGACATGTACAA \\
\hline \multirow[t]{4}{*}{ Mef2c } & Forward & GU252207 & RT & CACCGTAACTCGCCTGGTCT \\
\hline & Reverse & & RT & GCTTGCGGTTGCTGTTCATA \\
\hline & Forward & & ISH & GACAGAGACTGTGTGGTGTTCCCT \\
\hline & Reverse & & ISH & AGGTGGAGGGAGCTACCACTGTTA \\
\hline
\end{tabular}


Table 1: Primers used for cloning, sequencing, transcriptional analysis and probe synthesis (Continued)

\begin{tabular}{|c|c|c|c|c|}
\hline $\begin{array}{l}\text { Signalling } \\
\text { molecules }\end{array}$ & & & & \\
\hline \multirow[t]{2}{*}{ Bmp4 } & Forward & $\underline{\text { FJ195610 }}$ & RT & TCAAGTTGCCCATAGTCAGT \\
\hline & Reverse & & RT & CACCTGAACTCTACCAACCA \\
\hline \multirow[t]{2}{*}{ Bmp2 } & Forward & BT059611 & RT & ATGTGGTATTGCACCCATT \\
\hline & Reverse & & RT & ATGGACAGTTTCCCAATGA \\
\hline \multirow[t]{2}{*}{$\mathrm{Shh}^{*}$} & Forward & AY370830 & RT & CCGGCTCATGACTCAGAGATG \\
\hline & Reverse & & RT & TATCCCTGGCCACTGGTTCA \\
\hline \multirow[t]{2}{*}{ Ihh } & Forward & FJ195617 & RT & CAGATGACCCACTGGACTGAT \\
\hline & Reverse & & RT & GCTTGGTTGGGAGATATGCA \\
\hline \multicolumn{5}{|c|}{ Housekeeping gene } \\
\hline \multirow[t]{2}{*}{ Ef1a ** } & Forward & $\underline{\mathrm{DQ} 834870}$ & RT & CACCACCGGCCATCTGATCTACAA \\
\hline & Reverse & & RT & TCAGCAGCCTCCTTCTCGAACTTC \\
\hline
\end{tabular}

*Wargelius et al. [54] **Olsvik et al [52]

using Trizol reagent and Micro to Midi Kit ${ }^{\circ}$ (Invitrogen) before DNase treatment (DNase1, Invitrogen). The quality of the RNA was assessed spectrophotometrically (NanoDrop Technologies, DE, USA) $1 \mu \mathrm{g}$ RNA was reverse transcribed to cDNA using oligo(dT) primer and the Taqman Gold RT-PCR kit (Applied Biosystems). The cDNA synthesis was performed with 10 min primer incubation at $25^{\circ} \mathrm{C}, 1 \mathrm{~h}$ RT step at $48^{\circ} \mathrm{C}$ and 5 min RT inactivation at $95^{\circ} \mathrm{C}$. All reactions were performed in accordance to the manufacturer's protocol.

\section{Real-time quantitative RT-PCR}

Real-time qPCR was conducted using the Light cycler 480 and SYBR Green chemistry (Roche, Switzerland) at the following thermal cycling conditions: $95^{\circ} \mathrm{C}$ for $10 \mathrm{~min}$, followed by 45 cycles at $95^{\circ} \mathrm{C}$ for $15 \mathrm{~s}, 60 \pm 1^{\circ} \mathrm{C}$ for $15 \mathrm{~s}$ and $72^{\circ} \mathrm{C}$ for $15 \mathrm{~s}$. Further, specificity was assessed by the melting curves, determined post PCR $\left(95^{\circ} \mathrm{C}\right.$ for $15 \mathrm{~s}, 60 \pm$ ${ }^{\circ} \mathrm{C}$ for $1 \mathrm{~min}$ and $97^{\circ} \mathrm{C}$ continuous). To determine the efficiency of target genes and reference gene $(e f 1 a)$, we used the standard curve method. Relative target gene mRNA was normalized to relative efla mRNA levels for all sample, as recommended by Olsvik et al. [52]. The transcription ratios were analyzed using the Relative Expression Software Tool (REST) and tested for significance by the Pair Wise Fixed Reallocation Randomization Test ${ }^{\odot}$ [53].

\section{In situ hybridization}

Digoxigenin labeled antisense and sense riboprobes were synthesized according to the manufacturer's protocol (Roche), using $250 \mathrm{ng}$ of SP6 and T7 tailed PCR fragments as template. ISH was carried out on five $\mu \mathrm{m}$
Tw9100 sections as described [48], and microscopic analyses of the NBT/BCIP stained sections were conducted on a Zeiss Axio Observer Z1 equipped with an AxioCam MRc5 camera and AxioVision software (Carl Zeiss Microimaging $\mathrm{GmbH}$ ).

\section{Additional material}

Additional file 1 Sense probes. No staining was detected for ISH with sense probes. nc, notochord; ns, notochordal sheath, eb, endbone; tb, trabecular bone. Scale bar $=100 \mu \mathrm{m}$.

\section{Abbreviations}

Alp: alkaline phosphatase; BCIP/NBT: 5-bromo-4-chloro-3 indolyl phosphate $p$ toluidine salt/nitro blue tetrazolium chloride; Bmp: Bone morphogenetic proteins; Col1a1: collagen type 1a1; Col2a1: collagen type 2a1; Col10a1: collagen type 10a1; Ef1a: Elongation factor 1; Ihh: Indian hedge hog; IVD: intervertebral disk degeneration; IDD: Intervertebral disc disease; ISH: In situ hybridization; Mef2c: myocyte enhancer factor 2c; Mmp: Matrix metalloproteinase; PBS: phosphate-buffered saline; PFA: paraformaldehyde; qPCR: quantitative polymerase chain reaction; Runx2: runt-related transcription factor 2; Shh: Sonic hedge hog; Sox9: (sex determining region Y) box 9; TRAP: Tartrate resistant acid phosphatase.

\section{Authors' contributions}

EY participated in sampling, carried out the molecular studies, microscopic analyzes and acquisition and interpretation of data and drafted the manuscript. JT participated in the design of the ISH experiments, sequence alignment and probe design, microscopic analyzes and acquisition and interpretation of data. GB carried out the radiological diagnostics, accompanied in statistical analysis and participated in the experimental design. HT conceived the study and its experimental and molecular design, coordinated the sampling, and participated in acquisition and interpretation of data and in the drafting of the manuscript. All authors read and approved the final manuscript.

\section{Acknowledgements}

The authors are grateful to Asbjørn Valset, Britt Seljebø, and Kjellrun Gannestad for technical assistance during the project. The study was supported by The 
Norwegian Research Council (project no. 172483) and EU (COLL-CT-2005012451, FINE FISH).

\section{Author Details}

'Nofima Marin AS, Norwegian University of Life Sciences, NO-1432 Ås, Norway, 2Norwegian University of Life Sciences, NO-1432 Ås, Norway and ${ }^{3}$ AVS Chile SA, Imperial 0655, Of. 3A, Puerto Varas, Chile

Received: 26 February 2010 Accepted: 6 July 2010

Published: 6 July 2010

\section{References}

1. Lotz JC: Animal models of intervertebral disc degeneration - Lessons learned. Spine 2004, 29:2742-2750.

2. Renn J, Winkler C, Schartl M, Fischer R, Goerlich R: Zebralish and medaka as models for bone research including implications regarding spacerelated issues. Protoplasma 2006, 229:209-214

3. Suzuki H, Takahashi K, Yamagata M, Shimizu S, Moriya H, Yamazaki M: Spatial and temporal collagen gene expression in lumbar intertransverse fusion in the rabbit. Journal of Bone and Joint SurgeryBritish Volume 2001, 83B:760-766.

4. Urban JPG, Roberts S: Degeneration of the intervertebral disc. Arthritis Research \& Therapy 2003, 5:120-130

5. Roberts S, Evans H, Trivedi J, Menage J: Histology and pathology of the human intervertebral disc. Journal of Bone and Joint Surgery-American Volume 2006, 88A:10-14

6. Walmsley R: The development and growth of the intervertebral disc. Edinburgh Medical Journal 2009, 60:341-364.

7. Aunsmo A, Guttvik A, Midtlyng PJ, Larssen RB, Evensen O, Skjerve E: Association of spinal deformity and vaccine-induced abdominal lesions in harvest-sized Atlantic salmon,Salmo salar L. Journal of Fish Diseases 2008, 31:515-524.

8. Lewis LM, Lall SP, Witten PE: Morphological descriptions of the early stages of spine and vertebral development in hatchery-reared larval and juvenile Atlantic halibut (Hippoglossus hippoglossus). Aquaculture 2004, 241:47-59.

9. Berntssen MHG, Waagbo R, Toften H, Lundebye AK: Effects of dietary cadmium on calcium homeostasis, Ca mobilization and bone deformities in Atlantic salmon (Salmo salar L.) parr. Aquaculture Nutrition 2003, 9:175-183.

10. Koumoundouros G, Divanach P, Kentouri M: The effect of rearing conditions on development of saddleback syndrome and caudal fin deformities in Dentex dentex (L.). Aquaculture 2001, 200:285-304.

11. Lall SP, Lewis-MCCrea LM: Role of nutrients in skeletal metabolism and pathology in fish - An overview. Aquaculture 2007, 267:3-19.

12. Roy PK, Witten PE, Hall BK, Lall SP: Effects of dietary phosphorus on bone growth and mineralisation of vertebrae in haddock (Melanogrammus aeglefinus L.). Fish Physiology and Biochemistry 2002, 27:35-48.

13. Witten PE, Gil-Martens L, Huysseune A, Takle H, Hjelde K: Towards a classification and an understanding of developmental relationships of vertebral body malformations in Atlantic salmon (Salmo salar L.). Aquaculture 2009, 295:6-14.

14. Witten PE, Obach A, Huysseune A, Baeverfjord G: Vertebrae fusion in Atlantic salmon (Salmo salar): Development, aggravation and pathways of containment. Aquaculture 2006, 258:164-172.

15. Aubin JE: Bone stem cells. Journal of Cellular Biochemistry 1998:73-82.

16. Karsenty $\mathrm{G}$ : Bone formation and factors affecting this process. Matrix Biology 2000, 19:85-89.

17. Karsenty G: Minireview: Transcriptional control of osteoblast differentiation. Endocrinology 2001, 142:2731-2733.

18. Nishio Y, Dong YF, Paris M, O'Keefe RJ, Schwarz EM, Drissi H: Runx2mediated regulation of the zinc finger Osterix/Sp7 gene. Gene 2006, 372:62-70.

19. Bell DM, Leung KKH, Wheatley SC, Ng LJ, Zhou S, Ling KW, Sham MH, Koopman P, Tam PPL, Cheah KSE: SOX9 directly regulates the type-II collagen gene. Nature Genetics 1997, 16:174-178.

20. Arnold MA, Kim Y, Czubryt MP, Phan D, McAnally J, Qi X, Shelton JM, Richardson JA, Bassel-Duby R, Olson EN: MEF2C transcription factor controls chondrocyte hypertrophy and bone development. Developmental Cell 2007, 12:377-389.
21. Delaisse JM, Andersen TL, Engsig MT, Henriksen K, Troen T, Blavier L: Matrix metalloproteinases (MMP) and cathepsin K contribute differently to osteoclastic activities. Microscopy Research and Technique 2003, 61:504-513.

22. Ortega N, Behonick DJ, Werb Z: Matrix remodeling during endochondral ossification. Trends in Cell Biology 2004, 14:86-93.

23. Ytteborg E, Baeverfjord G, HK, Torgersen J, Takle H: Molecular pathology of vertebral deformities in hyperthermic Atlantic salmon (Salmo salar. BMC Physiology 2010 in press.

24. Yasui N, Sato M, Ochi T, Kimura T, Kawahata H, Kitamura Y, Nomura S: Three modes of ossification during distraction osteogenesis in the rat. Journal of Bone and Joint Surgery-British Volume 1997, 79B:824-830.

25. Witten PE, Gil-Martens L, Hall BK, Huysseune A, Obach A: Compressed vertebrae in Atlantic salmon Salmo salar: evidence for metaplastic chondrogenesis as a skeletogenic response late in ontogeny. Diseases of Aquatic Organisms 2005, 64:237-246.

26. Wlodarski KH, Wlodarski PK, Brodzikowska A: Metaplasia of chondrocytes into osteoblasts. Folia Biologica-Krakow 2006, 54:75-80.

27. Kvellestad A, Hoie S, Thorud K, Torud B, Lyngoy A: Platyspondyly and shortness of vertebral column in farmed Atlantic salmon Salmo salar in Norway - description and interpretation of pathologic changes. Diseases of Aquatic Organisms 2000, 39:97-108.

28. Cancedda FD, Gentili C, Manduca P, Cancedda R: Hypertrophic Chondrocytes Undergo Further Differentiation in Culture. Journal of Cell Biology 1992, 117:427-435

29. Lian JB, Mckee MD, Todd AM, Gerstenfeld LC: Induction of Bone-Related Proteins, Osteocalcin and Osteopontin, and Their Matrix Ultrastructural-Localization with Development of Chondrocyte Hypertrophy Invitro. Journal of Cellular Biochemistry 1993, 52:206-219.

30. Okafuji N, Liu ZJ, King GJ: Assessment of cell proliferation during mandibular distraction osteogenesis in the maturing rat. American Journal of Orthodontics and Dentofacial Orthopedics 2006, 130:612-621.

31. Amir $L R$, Everts $V$, Bronckers $A J$ : Bone regeneration during distraction osteogenesis. Odontology 2009, 97:63-75.

32. St-Jacques B, Hammerschmidt M, McMahon AP: Indian hedgehog signaling regulates proliferation and differentiation of chondrocytes and is essential for bone formation (vol 13,pg 2072, 1999). Genes \& Development 1999, 13:2617.

33. Akiyama H, Chaboissier MC, Martin JF, Schedl A, de Crombrugghe B: The transcrintion factor Sox9 has essential roles in successive steps of the chondrocyte differentiation pathway and is required for expression of Sox5 and Sox6. Genes \& Development 2002, 16:2813-2828.

34. Gersbach CA, Byers BA, Pavlath GK, Garcia AJ: Runx2/Cbfa1 stimulates transdifferentiation of primary skeletal myoblasts into a mineralizing osteoblastic phenotype. Experimental Cell Research 2004, 300:406-417.

35. Schenk RK, Spiro D, Wiener J: Cartilage Resorption in Tibial Epiphyseal Plate of Growing Rats. Journal of Cell Biology 1967, 34:275.

36. Anderson DG, Izzo MW, Hall DJ, Vaccaro AR, Hilibrand A, Arnold W, Tuan RS, Albert TJ: Comparative gene expression profiling of normal and degenerative discs - Analysis of a rabbit annular laceration model. Spine 2002, 27:1291-1296.

37. Guehring T, Omlor GW, Lorenz H, Bertram H, Steck E, Richter W, Carstens C, Kroeber M: Stimulation of gene expression and loss of anular architecture caused by experimental disc degeneration - An in vivo animal study. Spine 2005, 30:2510-2515.

38. Neidlinger-Wilke C, Wurtz K, Urban JPG, Borm W, Arand M, Ignatius A, Wilke HJ, Claes LE: Regulation of gene expression in intervertebral disc cells by low and high hydrostatic pressure. European Spine Journal 2006, 15:\$372-\$378

39. Krasnov A, Koskinen H, Pehkonen P, Rexroad CE, Afanasyev S, Molsa H: Gene expression in the brain and kidney of rainbow trout in response to handling stress. Bmc Genomics 2005, 6(1):3

40. Skugor S, Glover KA, Nilsen F, Krasnov A: Local and systemic gene expression responses of Atlantic salmon (Salmo salar L.) to infection with the salmon louse (Lepeophtheirus salmonis). Bmc Genomics 2008, 9:.

41. Takaishi $H$, Nemoto $O$, Shiota M, Kikuchi T, Yamada H, Yamagishi M, Yabe Y: Type-Il collagen gene expression is transiently upregulated in experimentally induced degeneration of rabbit intervertebral disc. Journal of Orthopaedic Research 1997, 15:528-538 
42. Johnson WEB, Eisenstein SM, Roberts S: Cell cluster formation in degenerate lumbar intervertebral discs is associated with increased disc cell proliferation. Connective Tissue Research 2001, 42:197-207.

43. Handa T, Ishihara H, Ohshima H, Osada R, Tsuji H, Obata K: Effects of hydrostatic pressure on matrix synthesis and matrix metalloproteinase production in the human lumbar intervertebral disc. Spine 1997, 22:1085-1091.

44. Bakay L, Cares HL, Smith RJ: Ossification in Region of Posterior Longitudinal Ligament As A Cause of Cervical Myelopathy. Journal of Neurology Neurosurgery and Psychiatry 1970, 33:263.

45. Resnick D: Case Report-240 - Fibrodysplasia Ossificans Progessiva (Fop) - Radiological and Gross Pathological Abnormalities in A Macerated Cadaver. Skeletal Radiology 1983, 10:131-136.

46. Lotz JC, Hsieh AH, Walsh AL, Palmer El, Chin JR: Mechanobiology of the intervertebral disc. Biochemical Society Transactions 2002, 30:853-858.

47. Prescher A: Anatomy and pathology of the aging spine. European Journal of Radiology 1998, 27:181-195.

48. Torgersen JS, Takle H, Andersen O: Localization of mRNAs and Proteins in Methyl Methacrylate (MMA) Embedded Tissues. Journal of Histochem Cytochem 2009, 57:825-830.

49. Bakke-McKellep AM, Penn MH, Salas PM, Refstie S, Sperstad S, LandsverkT, Ringo E, Krogdahl A: Effects of dietary soyabean meal, inulin and oxytetracycline on intestinal microbiota and epithelial cell stress, apoptosis and proliferation in the teleost Atlantic salmon (Salmo salar L.). British Journal of Nutrition 2007, 97:699-713.

50. Ortego LS, Hawkins WE, Walker WW, Krol RM, Benson WH: Detection of Proliferating Cell Nuclear Antigen in Tissues of 3 Small Fish Species. Biotechnic \& Histochemistry 1994, 69:317-323

51. Sanden M, Berntssen MHG, Krogdahl A, Hemre Gl, Bakke-McKellep AM: An examination of the intestinal tract of Atlantic salmon, Salmo salar $\mathrm{L}$ parr fed different varieties of soy and maize. Journal of Fish Diseases 2005, 28:317-330.

52. Olsvik PA, Lie KK, Jordal AEO, Nilsen TO, Hordvik I: Evaluation of potential reference genes in real-time RT-PCR studies of Atlantic salmon. BmC Molecular Biology 2005, 6:21

53. Pfaffl MW, Horgan GW, Dempfle L: Relative expression software tool (REST (c)) for group-wise comparison and statistical analysis of relative expression results in real-time PCR. Nucleic Acids Research 2002, 30:

54. Wargelius A, Fjelldal PG, Hansen T: Heat shock during early somitogenesis induces caudal vertebral column defects in Atlantic salmon (Salmo salar). Dev Genes Evol 2005, 215:350-357.

doi: $10.1186 / 1472-6793-10-13$

Cite this article as: Ytteborg et al., Morphological and molecular characterization of developing vertebral fusions using a teleost model BMC Physiology 2010, 10:13

Submit your next manuscript to BioMed Centra and take full advantage of:

- Convenient online submission

- Thorough peer review

- No space constraints or color figure charges

- Immediate publication on acceptance

- Inclusion in PubMed, CAS, Scopus and Google Scholar

- Research which is freely available for redistribution

Submit your manuscript at www.biomedcentral.com/submit
C Biomed Central 